\title{
3D models related to the publication: New material of Epiaceratherium and a new species of Mesaceratherium clear up the phylogeny of the early Rhinocerotidae (Perissodactyla)
}

\author{
Jérémy Tissier ${ }^{1,2 *}$, Pierre-Olivier Antoine ${ }^{3}$, Damien Becker ${ }^{1,2}$ \\ 1 Jurassica Museum, Route de Fontenais 21, CH-2900 Porrentruy, Switzerland \\ ${ }^{2}$ Département des Géosciences, Université de Fribourg, Chemin du Musée 6, CH-1700 Fribourg, Switzerland \\ ${ }^{3}$ Institut des Sciences de l'Évolution de Montpellier (ISEM, UMR 5554, CNRS/UM/IRD/EPHE), Université de Montpellier, place Eugène Bataillon, \\ 34095 Montpellier Cedex 05, France \\ *Corresponding author: jeremy.tissier@unifr.ch
}

\begin{abstract}
The present 3D Dataset contains two 3D models described in Tissier et al. 2020 (https://doi.org/10.1098/rsos.200633): the only known complete mandible of the early-branching rhinocerotoid Epiaceratherium magnum Uhlig, 1999, and a hypothetical reconstruction of the complete archetypic skull of Epiaceratherium Heissig, 1969, created by merging three cranial parts from three distinct Epiaceratherium species.
\end{abstract}

Keywords: Epiaceratherium, Molassitherium, Oligocene, Rhinocerotidae

Submitted:2020-04-16, published online:2020-07-15. https://doi.org/i10.18563/journal.m3.116

\section{INTRODUCTION}

The 3D models presented here have been described by Tissier et al. (in prep.). The mandible NMB.O.B.928 (Figure 1 and Table 1) assigned to Epiaceratherium magnum Uhlig, 1999 is housed in the Naturhistorisches Museum Basel (Switzerland). This is the most complete remain known to date attributed to this otherwise poorly known species. It notably shares the absence of third lower incisor and lower canine, the absence of lingual cingulum on the lower premolars and the usually-closed posterior valley on $\mathrm{p} 2$ with other species of the genus, i.e. $E$. bolcense Abel, 1910 and E. naduongense Böhme et al., 2013.

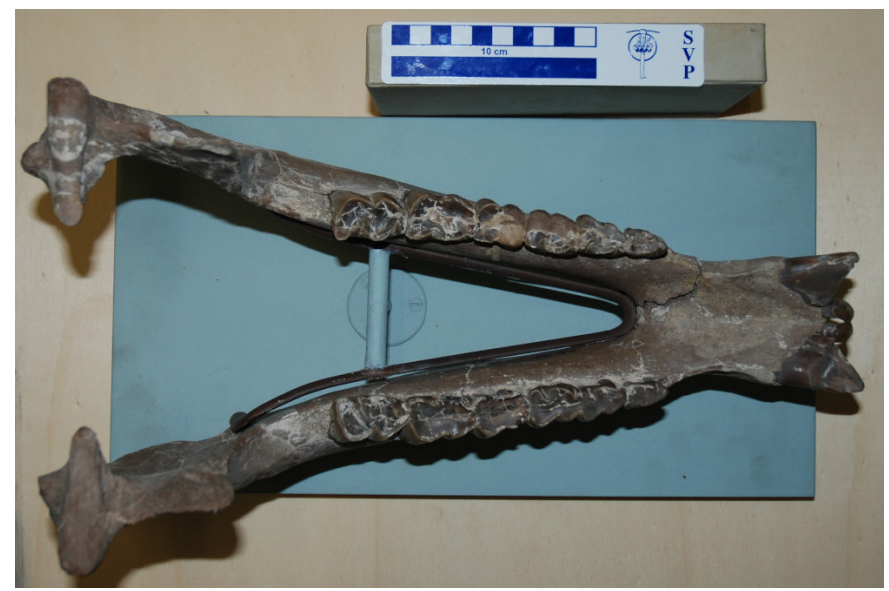

Figure 1. Mandible of the Oligocene rhinocerotid Epiaceratherium magnum Uhlig, 1999, from Rheinbetts, Switzerland (NMB.O.B.928). Scale bar $=10 \mathrm{~cm}$.

The new combination Epiaceratherium delemontense (Becker and Antoine, 2013) has also been proposed after a new phylogenetic analysis (Tissier et al., in prep.) instead of Molassitherium

\section{Model Id Description \\ M3\#534 Mandible of Epiaceratherium magnum (NMB.O.B.928) with texture file. \\ M3\#535 Archetypal reconstruction of the skull of Epia- ceratherium, generated by $3 \mathrm{D}$ virtual asso- ciation of the cranium of $E$. delemontense (MJSN POI007-245), mandible of E. mag- num (NMB.O.B.928) and snout of E. bolcense (NMB.I.O.43).}

Table 1. List of models. NMB: Naturhistorisches Museum Basel. MJSN: Musée jurassien des sciences naturelles, or Jurassica Museum.

delemontense Becker and Antoine, 2013. The generic assignment of this species has deep implications on its supposed anterior dentition because the anterior part of the type skull MJSN POI007-245 of E. delemontense is incompletely preserved and its anterior dentition is unknown. Thus, as a representative of Epiaceratherium Abel, 1910, we infer that it possessed a complete set of upper anterior teeth, i.e. three pairs of incisors and one pair of canines, which is typical of earliest-branching Rhinocerotidae but incompatible with the original attribution to the more derived rhinocerotid Molassitherium Becker and Antoine, 2013. Therefore, we propose here a hypothetical reconstruction of the archetypal skull of Epiaceratherium, illustrating this plesiomorphic anterior dentition (Figure 2 and Table 1).

\section{METHODS}

The specimens have been surface-scanned with a structuredlight scanner (Artec Space Spider) and reconstructed with Artec Studio 10 Professional. The 3D surface models are provided in .ply format and can be visualized with a wide range of freeware, such as MeshLab or MorphoDig. The specimen NMB.O.B.928 
can be visualized either with or without texture. The archetypic skull of Epiaceratherium was generated by virtually associating in Meshlab (v2016.12) the mandible NMB.O.B.928 of Epiaceratherium magnum to the holotype skull of Epiaceratherium delemontense (specimen number MJSN POI007-245; 3D model available in Maridet et al. 2019) as well as part of the snout of $E$. bolcense (NMB.I.O.43, described by Dal Piaz, 1930). This latter specimen only comprises the right side and was thus duplicated and reversed to fit the left side of the skull MJSN POI007-245. The Meshlab function "Flip X-axis" (without matrix freezing) from the "Filters $\rightarrow$ Normals, Curvatures and Orientation" menu was used to reverse it. They were then rotated and translated to fit the skull MJSN POI007-245, and the teeth as well as the maxillary foramen were used to associate them in an anatomically correct position. The nasal part of the snout of E. bolcense as well as the poorly preserved premaxillary part of the skull MJSN POI007-245 was "erased" using the command "Delete selected vertices", for esthetic purposes. The mandible NMB.O.B.928 was also rotated and translated, using the last molars and the mandibular condyles position as calibrations to anatomically fit the skull of E. delemontense. All visible layers were then flattened to create a single mesh and colors were applied using the "Z-painting" tool on each part to differentiate each specimen. We emphasize that this hypothetical skull is purely theoretical and does not have any anatomical value and should only be used as an archetypal representation of Epiaceratherium.

We are very grateful to Loïc Costeur (Naturhistorisches Museum Basel, Switzerland) who has allowed us studying the specimens housed in Basel. Grant sponsor: Swiss National Science Foundation. Grant number: 200021-162359.

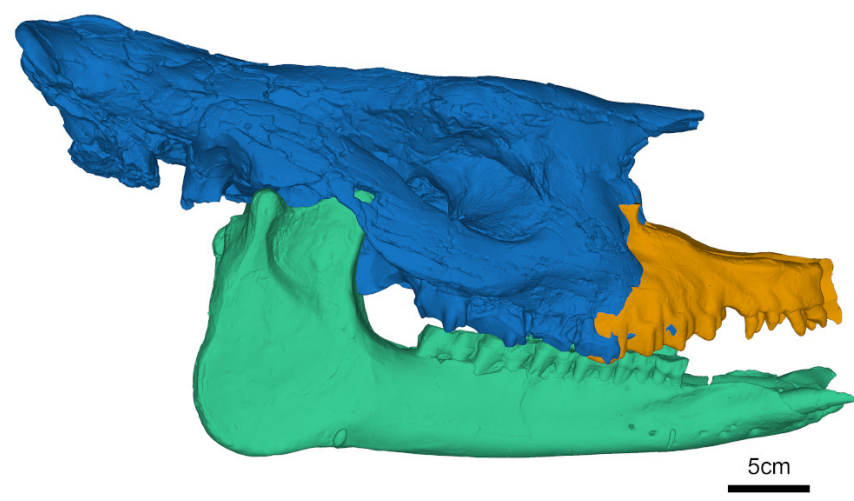

Figure 2. Archetypal reconstruction of the skull of the Oligocene rhinocerotid Epiaceratherium Abel, 1910, generated by 3D virtual association of the cranium of E. delemontense (Becker and Antoine, 2013), mandible of E. magnum Uhlig, 1999 and snout of E. bolcense Dal Piaz, 1930.

\section{BIBLIOGRAPHY}

Abel O. 1910. Kritische Untersuchung uber die palaogenen Rhinocerotiden Europas. Abhandlungen der Geologische Reichsanstall, Wien 20:1-52.

Becker D, Antoine P-O, Maridet O. 2013. A new genus of Rhinocerotidae (Mammalia, Perissodactyla) from the Oligocene of Europe. Journal of Systematic Palaeontology 11:947-972. https://doi.org/10.1080/14772019.2012.699007

Böhme M, Aiglstorfer M, Antoine P-O, Appel E, Havlik P, Métais G, Phuc LT, Schneider S, Setzer F, Tappert R, Tran DN, Uhl D, Prieto J. 2013. Na Duong (northern Vietnam) An exceptional window into Eocene ecosystems from Southeast Asia. Zitteliana Reihe A: Mitteilungen der Bayerischen Staatssammlung fur Palaontologie und Geologie 53:120-167.

Dal Piaz GB. 1930. I mammiferi dell'oligocene veneto: Trigonias ombonii. Padova: Societa Cooperativa Tipografica.

Maridet O, Rauber G, Rochat M, Roch R, Tissier J, Anquetin J, Becker D. 2019. 3D surface scan of the type specimen of Molassitherium delemontense Becker and Antoine, 2013: use of a 3D model for research and conservation issues. MorphoMuseuM 5:e82. https://doi.org/10.18563/journal.m3.82

Tissier J, Antoine PO, Becker D. In prep. New material of Epiaceratherium and a new species of Mesaceratherium clear up the phylogeny of the early Rhinocerotidae (Perissodactyla). Royal Society Open Science. https://doi.org/10.1098/rsos.2006 33

Uhlig U. 1999. Die Rhinocerotoidea (Mammalia) aus der unteroligozänen Spaltenfüllung Möhren 13 bei Treuchtlingen in Bayern. München: Verlag der Bayerischen Akademie der Wissenschaften Abhandlungen. Neue Folge, No. 170. 